\title{
ACTIONS, HABITS AND CONSTITUTION ${ }^{1}$
}

\author{
Bill Pollard
}

\begin{abstract}
In this paper I offer a critique of the view made popular by Davidson that rationalization is a species of causal explanation, and propose instead that in many cases the explanatory relation is constitutive. Given Davidson's conception of rationalization, which allows that a huge range of states gathered under the heading 'pro attitude' could rationalize an action, I argue that whilst the causal thesis may have some merit for some such 'attitudes', it has none for others. The problematic 'attitudes' are those which can be attributed to the agent only on the basis of her history of doing this sort of thing. In other words, they are among the agent's habits. I argue that such temporally extended states cannot be the causes of any present occurrence. Instead, I suggest we should think of the present action as partly constituting the state in question, and give a corresponding interpretation of the explanatory relation. Such explanations invite us to abandon a conception of agency narrowly based on psychology, in favour of an enriched one which takes an agent's habits to partly constitute the agent.
\end{abstract}

Davidson's 'Actions, Reasons, and Causes' remains the classic argument for the view that when we explain an action by giving the agent's reasons - we rationalize it - we are giving a form of causal explanation. ${ }^{2}$ Part of Davidson's argument turns on there being no satisfactory way of meeting the following challenge:

cause and effect form the sort of pattern that explains the effect, in a sense of 'explain' that we understand as well as any. If reason and action illustrate a different pattern of explanation, that pattern must be identified. ${ }^{3}$

${ }^{1}$ This is a preprint of an article accepted for publication in Ratio (c) 2005 Bill Pollard. It is scheduled to appear in volume XIX, 2006.

2 Donald Davidson, 'Actions, Reasons, and Causes', Journal of Philosophy, 60 (1963), reprinted in his Essays on Actions and Events (Oxford: Clarendon Press, 1980), pp. 3-21. Page references are to the reprint.

3 'Actions, Reasons, and Causes', p. 10. 
A small number of writers have met Davidson's challenge head-on, that is by identifying a 'pattern of explanation' which is not causal. For instance, Arthur Collins and Rowland Stout have both proposed that rationalization is rather a form of teleological explanation. ${ }^{4}$ The thought is that when we name a primary reason, we explain the action in terms of an outcome or goal sought by the agent. ${ }^{5}$ But whilst this teleological view undoubtedly enjoys some plausibility, and in the hands of these writers is far less mysterious than Davidson supposes, and is even scientifically respectable, it still has problems.

One particular problem which I shall mention but not argue for, is that is not at all clear what goal is being pursued when an action is rationalized by 'social conventions' or 'character traits which show themselves in a lifetime of behaviour', these being legitimate rationalizers on Davidson's account. For it seems quite open to an opponent to flatly deny that agents have any goal, either explicitly or implicitly, when they perform actions, say, of a kind that they have picked up during upbringing. Think of our ways of speaking and interacting socially. Even if it may be possible to attribute purposes to many such activities ('to communicate'?, 'to get on with one another'?), it does not follow that individual agents have such purposes in participating in them. From the agent's point of view, these could be things that she 'just does', and not even for 'the sake of doing them'. Any attempt to attribute a goal just looks to be a consequence of a prior theoretical conviction, rather than an independent datum with which any theory must cope. Whether or not this is a decisive objection to the teleological view, my suspicion is that the teleological theorists accept the terms of Davidson's challenge too uncritically. And that is something I want to avoid here.

${ }^{4}$ Arthur C. Collins, The Nature of Mental Things (Notre Dame, Indiana: University of Notre Dame Press, 1987); Rowland Stout, Things That Happen Because They Should: A Teleological Approach to Action (Oxford: Clarendon Press, 1996).

${ }^{5}$ Collins, for instance, writes: 'a man who explains performing one action by saying that it belonged to a class of actions toward each of which he had a pro attitude is, at the same time, committing himself to the assertion that had the performed action been inefficacious in attaining the goal that defines the class in question, then (in the absence of countervailing reasons) he would have performed one or more other such actions in order to secure the goal.', The Nature of Mental Things, p. 143. 
I want to propose that Davidson's notion of a pro attitude lies at the root of the problem of identifying the sought pattern of explanation. At his own admission, this notion does 'yeoman service' for him in covering a huge range of the agent's 'attitudes'. But whilst this notion may serve the end of unification very well, it does so at the cost of running together notions which play very different explanatory roles. It is my contention that once we have drawn a distinction between two sorts of pro attitude, we shall obtain a fresh view of how the supposedly unitary notion of rationalization could be understood. This will cast doubt on whether there is any real unity to be had.

I shall distinguish between two classes of pro attitudes: those which, for reasons that will become clear, I shall call 'habits', and those which do not fall into this category. Once this distinction is drawn, we will see why the causal interpretation fails when habits make up a primary reason. This leads to my proposal that there is a third interpretation available for such rationalizations, which is neither causal nor teleological, but what I call constitutive. Roughly, the idea is that when we explain an action by means of a pro attitude which is a habit, we are identifying that action as one amongst many similar actions distributed across that agent's career.

One of the advantages with interpreting this class of rationalizations as constitutive is that the usual link to the agent's psychology is simply absent. But this will also be thought to be a problem. For on a standard view, it is the link to psychology which is supposed to confer authorship on the behaviour in question. The story is that the behaviour is my action because it is me who has the belief-pro attitude pair in my psychological make-up, to which the behaviour in question is suitably related. If constitutive explanations are not psychological, then, but rather refer to patterns of behaviour, it becomes unclear how they carry with them the notion of authorship, as they presumably must if they are to be considered to be explanations of actions. I argue that the perceived difficulty here is due to an overly narrow conception of agency which requires psychology to underwrite authorship. I propose instead that habits carry with them a conception of authorship, since their exercise reveals an aspect of who that person is. This then is a second way in which the relation of constitution is important in understanding this class of action explanations. For the relation between an agent and her habits is also constitutive: agents are, at least partly, constituted by their habits.

I should note that whilst my argument is explicitly directed at Davidson's position, it has more general scope. In particular, my argument also applies to 'neo-Humean' views 
which suppose that all actions are explained, as well as rationalized, by a belief (on the side of Humean 'reason') and a desire (on the side of 'passion'). Here the notion of a 'desire' is doing the same catch-all work as the Davidsonian pro attitude, and is subject to the same critique.

Given the anti-intellectualist flavour of my argument, one might think that the proposals of Gilbert Ryle will provide important support, though the association may also invite established criticism. ${ }^{6}$ But my debt to Ryle will here be implicit. For whilst I share with him an opposition to an intellectualism that overplays our capacities for reasoning, I do not agree that habits cannot further that end. ${ }^{7}$ I speculate that an important factor in the unpopularity of habits as explanatory items in twentieth century philosophy has been their unfortunate association with 'behaviourist' psychology. ${ }^{8}$ But that was no reason for Ryle to reject them then, and it is no reason for us to do so now. For it is not hard to resist critiques which offer crass caricatures of the notion of habit, and/or assume we are proffering some sort of reduction.

I begin in $\S 1$ by drawing the distinction between the two sorts of state that Davidson's notion of pro attitude runs together. In §2 I express some doubts about the role of belief in making up a primary reason. I then argue in $\S 3$ that for habits, the causal interpretation is implausible. In $\S 4$ I offer an alternative interpretation of the explanatory relation as a form of constitutive explanation. In §5 I spell out how understanding the relation in this way yields a distinctive sense in which actions are related to agents.

${ }^{6}$ See especially The Concept of Mind (Penguin, 1949).

7 Ryle writes: 'the common assumption that all second natures are mere habits obliterates distinctions which are of cardinal importance for the inquiries in which we are engaged' (The Concept of Mind, p. 42). He argues (pp. 41-4) that the notion of an 'intelligent capacity' is to be preferred. For criticism see Nathan Brett, 'Human Habits', Canadian Journal of Philosophy, 11 (1981), pp. 357-76.

8 J. B. Watson, Psychology from the Standpoint of a Behaviourist (Philadelphia, 1919); B. F. Skinner, Science and Human Behaviour (New York, 1953). 


\section{Two Sorts of Pro Attitude}

Davidson is well aware that the content of rationalizations should not be restricted to psychological states. For him, a primary reason, which is to rationalize everything worthy to be deemed an action, consists in two elements: (a) a 'some sort of pro attitude towards actions of a certain kind, and (b) believing (or knowing, perceiving, noticing remembering) that his action is of that kind'. 9 In this section I shall focus on Davidson's notion of a pro attitude, and address the role of belief in $\S 2$.

Under the heading 'pro attitude' are to be included:

desires, wantings, urges, promptings, and a great variety of moral views, aesthetic principles, economic prejudices, social conventions, and public and private goals and values in so far as these can be interpreted as attitudes of an agent directed towards actions of a certain kind. The word 'attitude' does yeoman service here, for it must cover not only permanent character traits that show themselves in a lifetime of behaviour, like love of children or a taste for loud company, but also the most passing fancy that prompts a unique action, like a sudden desire to touch a woman's elbow. ${ }^{10}$

Here Davidson unashamedly simplifies our lives (both theoretical and otherwise) by grouping a diversity of states under the same heading. And of course all else being equal, simplicity is what we would like in a theory. But I don't think all else is equal. For I think that Davidson's notion of a pro attitude runs together two classes of states which have very different explanatory roles. My argument begins by keeping these classes distinct.

I want to distinguish between pro attitudes which are attributed to agents only given a certain sort of repeated behavioural history and present proficiency, and those which are not. I call the former class 'habits', and the latter 'non-habits' (though 'occurrences' might be a better term for many of them). By using this term I don't mean to imply too close an association with 'bad' habits, like nail-biting. For although they are perhaps less often remarked upon, we all have many habits which are not bad, but which help us negotiate our familiar environment and interact with one another. Some of these habits are widely shared, whilst others are characteristic of particular individuals.

\footnotetext{
9 'Actions, Reasons, and Causes', pp. 3-4.

10 'Actions, Reasons, and Causes', p. 4.
} 
I shall say, then, that a given pro attitude is a habit if (i) it refers to a pattern of behaviour that the agent has gone in for with some past regularity, perhaps in characteristic circumstances. It therefore cannot be attributed on the basis of a single action, or no action at all. (ii) The agent can now perform this sort of behaviour 'automatically', in a sense to be clarified. The crucial feature of this second condition is that it ensures that the repetition in (i) is not purely accidental.

Just how we understand the automaticity of the exercises of habits is not a straightforward matter. However, we can appeal to some intuitions to give a rough account which will suffice here. Anthony Kenny writes that, 'If one has a habit of doing X, then it is harder not to do $\mathrm{X}$ than if one has not'.11 So it seems that some sort of effort is required if one is to do something other than $X$. Let us assume that this effort is in deliberating and/or choosing to do something else. The implication is that it is a lack of such effort which makes a behaviour automatic. When one is in the right sort of circumstances, one just does $X$. One mark of this automaticity is the experience of 'finding oneself' doing $X$, though any surprise can be accounted for in one's lack of prior thought, rather than in terms of what one is doing, which is after all, very familiar. The idea that habits are automatic in this way is supported by the familiar fact that thinking about the performance of an action which is usually habitual often leads to a rather less than perfect performance.

We can now divide Davidson's list of pro attitudes as follows. First, and most obviously, the two 'character traits that show themselves in a lifetime of behaviour' are habits. Had the agent not indulged her love of children or taste for loud company in her lifetime, it would be false to say that she has such traits, and that would be true quite independently of some particular action which might be thought to be such an indulgence. There is no such thing as a character trait that has never been manifested. What is more, I think it is fair to say that character traits can be manifested automatically by the agent, which is to say that whilst they may deliberate or choose to exhibit this character trait on many occasions, they need not do so. It may be true that some character traits are not manifested automatically, but as long as some of them are, we can simply include these as amongst the pro attitudes in question.

${ }^{11}$ Anthony Kenny, The Metaphysics of Mind (Oxford: Clarendon Press, 1989), p. 85. 
Most clearly on the non-habit side of the distinction would be 'desires', 'wantings', 'urges', 'promptings' as well as the slightly disturbing 'sudden desire to touch a woman's elbow'. Let us agree with Davidson that these pro attitudes can arise in us and may result in some particular action (however that relation may be understood). Let us also say that we need not examine the agent's history of doing this sort of thing for their attribution to be plausible. Indeed an agent may be said to have one of these attitudes without ever acting on it. These pro attitudes are therefore not habits.

As for the other pro attitudes Davidson presents us with, it is not immediately clear which side of the divide we should place them on. But that is because the distinction I have drawn cuts across the classes in question, and we would need to know more about particular instances to classify them. For instance, a 'moral view', we might hope, is not something that an agent pays mere lip-service to, but rather has manifested itself in her history, and present fluency, as would be the case for a properly inculcated virtue. In such a case a 'moral view' would be a habit. But we also talk of agents having 'moral views', when we mean matters of expressed opinion on certain controversies, such as euthanasia or war, and there need be no implication that the agent has acted upon these views, or indeed ever will. These would not be habits. I take it that 'aesthetic principles', 'economic prejudices', 'social conventions', and 'public and private goals and values' can be treated in a similar way, some in each class being habits, others not.

As I have said, I think this distinction within the class of pro attitudes is of fundamental importance in the context of deciding on the kind of explanation rationalization represents.12 But before I can argue for that view, we need to tidy up the issue of the belief component of a primary reason in the context of this distinction.

\section{Beliefs}

Davidson's inclusion of what I call habits in the class of pro attitudes presents a prima facie difficulty for the causal interpretation. After all, there must be some datable event which can count as the cause, and a habit such as a character trait might, as Davidson admits, show itself only in 'a lifetime of behaviour'. Davidson's solution is to conceive of the pro attitude

12 Admittedly, this distinction may not be decisive in deciding between the causal and teleological interpretations, though as I suggested in the introduction, habits may cast doubt on the teleologist's assumption that all pro attitudes entail a goal. 
as only one element of the cause, the other being the state of believing grouped under (b) in the earlier quote. It is the 'onset' of such states (like one's coming to believe some candidate action would result in loud company) which combine with such pro attitudes to constitute the event which is the cause. But I want to suggest that we lack grounds for attributing such beliefs.

It seems to me that it is at least highly contentious to say that we are right to attribute such states of believing to an agent in every case of intentional action, and the manifestations of habits provide a particularly pertinent set of counter examples. After all, such beliefs must be plausibly attributable to the agent not simply as a consequence of the fact that she had acted in a given way, since it is the actions which are supposed to result from the belief, and not the other way around. There must then be independent grounds for attributing the belief to the agent. And I doubt such grounds can be found.

According to Davidson's own project these grounds would have to be found in other things she says or does, provided we make the charitable assumption that the agent is rational. The problem is that the required belief has a highly specific content concerning the kind of action that was in prospect. And it does not seem at all likely that the agent would self-ascribe such a belief, either before, after or during her action, even given the right sort of questioning. Persuading her that she doesn't disbelieve that that her action is, was or will be of a given kind (that it wouldn't result in loud company), which might plausibly yield assent, is hardly sufficient to ascribe the corresponding positive belief to her (that it would) with any confidence.

After all, one notable feature of habits is that people with them may be quite ignorant of the fact that they have them. They may have been acquired from a very young age, or quite inadvertently, and the agent simply hasn't reflected on them since. Indeed the experts on such things tend to be close friends, spouses, and other intimates. And the agent herself might consistently and sincerely deny the attribution of a habit ('I don't have a taste for loud company!'), and in such a case, the attribution of a belief that some action would indulge this habit, would seem just plain wrong.

Even if we depart from Davidson's interpretive project, things are hardly more favourable. If we consider phenomenology, for example, cases in which a belief with the required content were explicitly present to an agent's consciousness either before she acts, or at the time of acting, would presumably be rather rare. 
Denying that beliefs with the required content can be ascribed to the agent is not of course to deny that any belief at all can be ascribed to her, and nor indeed that other such beliefs might not feature in a full explanation of the action in question. After all, the exercise of a habit, even though it is automatic, presumably often requires a sensitivity to the circumstances in which the habit is characteristically exercised (in the example, it might be the presence of loud voices coming from the next room). Some sort of perception then would seem to be implicit in the fact that the an agent acted out of habit. But not only would it be highly unlikely that the agent would reliably self-ascribe these perceptions, for reasons analogous to those for self-ascribing the habit itself, but most pertinently, the perceptions in question would not have the right content for the Davidsonian scheme.

Davidson's putative states of believing, then, the onset of which is essential to the causal account when the pro attitude is a habit, look like the posits of somebody in the grip of a theory, rather than an independent datum being innocently incorporated into a theory whose correctness is still up for grabs. It seems to me then that with such pro attitudes, we should be prepared to delete a belief with that particular content altogether in our attribution of a reason to the agent. Mentioning the pro attitude alone should still disclose something of the attractiveness to the agent of the action in question, for the agent can on this ground alone be said to have an 'attitude' towards actions which manifest the habit. If there is to be a belief the onset of which is to be a candidate cause, it will have to have a content rather different from that required by Davidson's scheme.

Here then are some reasons to be suspicious of the belief requirement in the context of doubts about the causal interpretation. Accordingly I shall proceed without this requirement. In due course we shall see why this requirement can be jettisoned altogether.

\section{Habits and Causes}

Do pro attitudes causally explain actions? When we consider some of those which Davidson lists, we might think a positive answer is worth consideration. For instance, when we experience an 'urge', like a pang of hunger, we can at least locate a suitable event. Given this, the thesis that the explanatory relation is causal at least gets off the ground. But there are no such intuitions for the class of pro attitudes I have called habits. There is no

phenomenology to having a habit (as opposed to exercising one), and nothing which would 
seem to count of the 'onset' of a habit which is separable from its initial exercises. So the causal interpretation looks unpromising. ${ }^{13}$

Nevertheless it cannot be denied that the idea that habits cause actions enjoys both common-sense and theoretical appeal. We sometimes say of an action that it was done through 'force of habit', presumably the force in question being causal. The causal view will also be attractive to those who, like Davidson, seek an account of agency which is 'naturalistic', given a popular interpretation of that idea. According to that interpretation, our aim is to view all intentional phenomena, including mental states and actions, as entering into the same sorts of relations as the non-intentional, physical furniture of the world, these relations being paradigmatically causal. The thought is that causal explanations explain 'in a sense of "explain" that we understand as well as any'.14 If habits were causes, perhaps in the same way as the physical dispositions standardly discussed by philosophers, such as brittleness and elasticity, are causes, this naturalistic picture could be significantly advanced. But I don't think habits can be causes.

Part of the problem is that habits are not like the standard sorts of dispositions mentioned above. As philosophers writing on such matters are fond of pointing out, standard dispositions need not have been manifested by the sample in question, for those properties to be correctly attributed to that sample. This fact supposedly generates a certain problem about how to distinguish between two 'untested particulars', one of which has the disposition, whilst the other lacks it. And this problem is standardly given a metaphysical solution, according to which the disposition is ultimately constituted by the sample's microstructure, or some metaphysical analogue. ${ }^{15}$

${ }^{13}$ Supporters of the teleological interpretation could point out that agents aim at 'satisfying' urges. But it is very unclear what an agent exercising a habit could be construed as aiming at: that the habit 'be exercised', or doing the 'easy (most natural)' thing? Again, the interpretative strain in attributing such aims is palpable.

14 'Actions, Reasons, and Causes', p. 10.

${ }^{15}$ Stephen Mumford, for instance, proposes a 'realist' analysis of dispositions, which posits a 'categorical base' which one sample has, and the other lacks. See his Dispositions (Oxford: Oxford University Press, 1998) p. 29. 
However, when we look at habits, we see (from condition (i) given in §1) that a person with a particular habit is logically required to have a certain sort of history. If somebody has never $\Phi$-ed before, it is simply false to say that they have the habit of $\Phi$-ing. Thus in the case of habits, there is no such thing as an 'untested particular', and hence no problem of how to distinguish between two of them. An agent's past plus features of her present action (that it is done automatically, from condition (ii)) are sufficient for us to decide whether she has a particular habit or not. To capture the idea, we need not say that there is anything more (or indeed less) to having a habit than that. Whether or not metaphysics is required to analyse the standard dispositions, it is not required here.

But given that habits necessarily have manifestations, there is a second, more serious problem for the view that they are causes. The problem is this. If it were true that habits cause their exercises, both habit and exercise must be specifiable independently. In Hume's terms, they must be 'logically distinct existences'. Now, we need not think that there is a problem with specifying the explanandum, a particular exercise of a habit, independently of the habit of which it is an exercise. We can speak of 'my seeking out loud company' without implying that I have done it habitually. It might be the first time I have ever done it, or I might only do it sporadically. The problem comes when we try to specify our explanans, the habit, independently of the explanandum, its particular exercise.

The problem is that explanations in terms of a habit are, in a sense, 'self-fulfilling'. When we refer to a habit, we refer to an entity which is composed of the totality of its exercises, and that includes the very action that is being explained. We would be underspecifying the habit were we to omit the present action from its constitution. After all, if the habit explanation is right, and the action is indeed explained by the habit, then that very action contributes to the truth of the claim that the person has that habit. So the sense in which habit explanations are self-fulfilling is that their very correctness makes them more plausible!

What this means, however, is that habit explanations cannot be causal explanations, for in specifying the habit, we specify (amongst other actions) the action to be explained itself. The two are not logically distinct existences, since the explanans is a part of the explanandum. To say that habits cause their exercises would be as logically confused as saying that the sound of the symphony causes the sound of the violins. The explanatory relation, then, cannot be causal. 
This is not to deny that exercises of habits and habits themselves are dependent upon causal processes. On the contrary, they are totally dependent on many such processes working correctly, be they processes in the perceptual system, the brain or the muscles, and in the external environment co-operating in various ways. What is denied is that when we explain an action in terms of a habit, we are referring to any such processes. And this need not close the door on naturalism, since there are alternative interpretations of this idea. ${ }^{16}$

If this is right, we have a clear ontological case for resisting causal interpretation of explanations which employ a habit as a pro attitude.

\section{Constitution}

Even if we can overcome the difficulties with the ascription of belief outlined in $\S 2$, if the argument of $\S 3$ is right, it follows that when a primary reason involves a pro attitude which is a habit, we have, in Davidson's terms, no 'account of the "mysterious connection" between reason and action'.17 I now want to address this problem directly by giving an account of a kind of explanation which is neither causal nor teleological, but naturally arises out of the difficulties with the causal relation described above. This is constitutive explanation.

By constitutive explanation I mean the sort of explanation we give when we explain something by saying that it is a part of - constitutes - something else. Examples would include explaining what a particular cell is by saying that it is part of a larger organism; explaining what a broom-handle is by saying it is part of a broom; or explaining Bob's attendance at a lecture by saying it is part of his degree course. I propose that when we give a habit explanation we are doing something of the same sort. We are explaining what an action is by saying it is part of somebody's habit.

I should stress that by constitution I do not mean identity. Some writers defend a view according to which if a plant is constituted by the cells that make it up, then the plant is

16 For a construal of naturalism which does not require that reasons are causes, see John McDowell, Mind and World (Cambridge and London: Harvard University Press, 1996). For the claim that such a naturalism actually depends upon a properly worked out notion of habit, see my 'Naturalizing the Space of Reasons', International Journal of Philosophical Studies, 13 (2005), pp. 69-82.

17 'Actions, Reasons, and Causes', p. 11. 
identical to those cells. ${ }^{18}$ If this were right I would be committed to saying that a habit is identical to its exercises, and I do not want to do that, not least because it makes it problematic how a habit could itself be explanatory. If a habit were really nothing but the totality of its exercises, the similarity of the exercises might be purely accidental, and hence could not really explain anything. But the relation of constitution I have in mind allows that an entity can be said to be composed of other entities without remainder, but that entity is still distinct from the totality of those entities. After all, it can have properties and stand in relations that the totality cannot. A plant can be healthy, or belong to me, and a habit can be hard to break, or irritating. Like plants, habits are genuine entities in their own rights.

It might be objected however, that the relation of constitution prevents us from saying that a habit persists even when it is not being exercised, which is something we do say, so our account should not have this consequence. One approach which might be thought to solve this problem is to take a metaphysical approach to habits like that standardly taken with dispositions, and mentioned in $\$ 3$ above. According to such an approach the metaphysical base (whatever that is) persists and underwrites the habit's persistence. But since this distorts the phenomenon of habit by assimilating it to nonhistorically-grounded phenomena, I think we should take another approach.

What I think creates the apparent problem of persistence is that the standard examples of constitutive relations are synchronic, that is, they obtain at a given moment in time. So a plant is constituted by a collection of cells at any given time (though the same plant may at different times not be constituted by the same collection of cells). The plant depends on the cells for its existence in the sense that were there no collection of cells at all at any given time, there would be no plant. But on the present proposal a habit is constituted by a set of actions all of which exist (or existed) at different times. So it is still hard to see how we can say that a habit exists between its exercises. It looks like we can only say it exists at the same time as its constituent exercises.

But I think we can save the relation by distinguishing between constitution at a time from constitution across time. The former applies to plants, brooms, and other composite

\footnotetext{
18 E.g. Michael Burke, 'Copper Statues and Pieces of Copper', Analysis, 52 (1992), pp. 12-17; Eric Olson, 'Material Coincidence and the Indiscernibility Problem', Philosophical Quarterly, 51 (2001), pp. 337-55.
} 
objects. The latter applies to entities whose constituents are spread across time, and may not be contiguous, like somebody's doing a philosophy degree, building a house, or (I want to say) having a habit. We could I think correctly say that Bob's doing a philosophy degree consists in activities such as attendance at lectures, writing of essays, revision, and exams. Doing the degree is made up of these distinct activities, and if he didn't do any of these things, he would not be doing a philosophy degree at all. What is more, we can time the beginning of his doing the degree as simultaneous with Bob's involvement with the first constituting activity, and its ending as simultaneous with the last. What we would not be forced to do therefore, is to deny that when Bob is having a drink, visiting home, or sleeping, that he is still doing his degree. For whilst these are not constituents of the larger activity, they take place within the timeframe of that larger activity. So constitution across time works differently from constitution at a time. If we conceive of the constitution of habits in this way we have no difficulty in saying both that a habit is constituted by its exercises, and that it persists even when it is not being exercised.

What I propose, then, is that when we give an explanation which features a habit, we are not explaining the action in terms of causes, but in terms of one of its formal properties, namely, that portion of the agent's career of which the present action is a part. When we explain an action by mentioning a pro attitude which is a habit, then, this contextualising is the means by which we explain it.

This gives us a reply to what is perhaps Davidson's best argument for the causal interpretation of rationalization. He points out that 'a person can have a reason for an action, and perform the action, and yet this not be the reason why he did it. Central to the relation between reason and an action it explains is the idea that the agent performed the action because he had the reason'.19 Davidson thinks that because of a lack of alternatives, the 'because' must be causal. So we can say that what distinguishes the reasons for which the agent could have acted but didn't, from the one for which she did act, is that the latter is the one which caused the action. In the context of habits, I think we can now say that what is distinctive about the 'reason' for which the agent acted is that only that 'reason' (i.e. habit) is one of which the action is constitutive. This is an invitation to look more broadly at the agent's earlier career, rather than more narrowly, at forces operating inside her.

\footnotetext{
19 'Actions, Reasons, and Causes', p. 9.
} 
We can also now see why the belief component of the Davidsonian primary reason is otiose. For it does not play any role at all in a constitutive explanation. So if we don't want to distort things, we should say that when a pro attitude is a habit, we do not need to insist on a belief to complete the reason, for that just looks like a consequence of an assumed causal interpretation. For the habit is sufficient on its own. ${ }^{20}$

It is possible to think that this last move actually weakens the case against Davidson. For if we indeed lack a primary reason for behaviours which are to be explained by habits, that just disqualifies them from being actions, or at least not intentional actions. After all, for Davidson, intentional actions are by definition, those events which are, under their intentional description, rationalized by a primary reason.

I certainly want to reject the conception of action proper implicit in this sort of objection. But I am not going to have space to provide anything like a convincing account of what action proper amounts to, which would be hospitable to those which are habitual. Rather, I shall mention two reasons for thinking that habitual actions are actions proper, before expanding on a third.

First, I think there is a sense in which habitual actions are intentional, though not in the sense that Davidson understands that notion. Rather, the intentionality in habitual actions is an intrinsic to them, rather than being conferred upon them by some separable prior state of intention. ${ }^{21}$

Second, I think that habitual actions deserve to be regarded as actions in view of the control we have over them, specifically, in the standing possibility of intervening, in a direct

20 If this is right, we might also reconsider whether a habit explanation should properly be regarded as a 'reasons' explanation at all. After all, a habit does not work as a consideration which makes the action seem attractive to the agent. Rather, it is a way in which the agent is orientated prior to any considerations coming to light, and is what could give those considerations their relevance and power to motivate. Bernard Williams makes an analogous point regarding moral habits (virtues), which, he says, 'are not an element of firstpersonal deliberation', Ethics and the Limits of Philosophy (London: Fontana Press, Collins, 1985), p. 11.

${ }^{21}$ An example of such an account of intentionality is John Searle's 'intentionality in action' from his Intentionality (Cambridge: Cambridge University Press, 1983). 
way, in their inception or progress. ${ }^{22}$ The same cannot be said, for example, of compulsions, phobias and addictions, conditions with which habits are often confused. ${ }^{23}$

What I want to say a little more about here, since it also involves constitution, is a third way in which habitual actions deserve to be regarded as actions proper, which is to do with how they are related to agency despite their being explicable by patterns of behaviour.

\section{Agency}

The thought I want to develop may be familiar from Aristotle, and those who follow him, in giving idea of virtue centrality in accounts of specifically moral agency. I will then generalise this thought to explicate an aspect of agency as such.

The thought is this. One important argument for our requiring a notion of virtue in an account of moral agency is that if one does not act from a 'firm and unalterable character' serious doubt is cast on one's authorship of the action in question. ${ }^{24}$ This needs some qualification in the context of habits. For it is no part of my claim that habits be literally 'unalterable', though they may be hard to alter. But I would think the same could be said of the virtues to the extent that we imperfect beings have them, as opposed to how we would have them ideally, the latter being Aristotle's focus in the passage quoted. The key point is that the stability or reliability of what one does is somehow essential to one's status as it's author.

To illustrate this we can contrast two ways in which somebody might be said to act 'courageously'. Consider A, who has the virtue of courage in the full sense that she has done courageous things before, now does so automatically when it is called for. Compare B, who has never done a courageous thing in her life, but nevertheless in the same situation, manages to do just what the courageous person would do in this situation, that is, just what A does. Whilst there is no doubt that A is fully responsible for her acting, the same is not

\footnotetext{
22 The directness of such intervention distinguishes it from intervention of an indirect sort, such as that which might be exercised over somebody else's behaviour, say by physical restraint.

${ }^{23}$ For more on intervention control see $\S 2$ of my 'Can Virtuous Actions be Both Habitual and Rational?', Ethical Theory and Moral Practice, 6 (2003), pp. 411-25.

${ }^{24}$ Nicomachean Ethics, 1105a32-3.
} 
true of B. Since B has only managed to act courageously on this occasion, she has not shown, as it were, her commitment to acting in this way. She acts in the sort of way a novice might act, who is only currently acquiring the virtue; or perhaps in the way an actress on a stage might imitate somebody with the virtue. This lack of commitment is not here to be understood as a lack of thought, which might be thought somehow to transform the character of the action, but rather as a lack of past action, in circumstances in which acting courageously would have been appropriate. And this leaves the question of whether thought is lacking from such actions, quite open. What is crucial is that through her inaction she has not made this sort of behaviour part of her (second) nature; acting in this way is not part of who she is. The extent to which such an agent is the author of such actions is only the extent to which it was she who made an effort to be courageous, or she who had the skill of imitation. But she falls short of being authentically courageous. ${ }^{25}$

Whilst this sort of point may be reasonably well known in discussions about virtue, it's significance for agency quite generally has, I think, been underestimated.26 What I want to suggest is that since moral habits (virtues) confer specifically moral authorship, then we can also say that habits, quite generally, confer authorship simpliciter. The particular features of specific virtues, important to human flourishing though they may be, serve to mark them out from the many other habits an individual agent may have, be they good, bad or indifferent. Whichever a habit is, it is part of what it is to be that person, and when they exercise a habit, they thereby show a part of themselves to us. Quite generally, then, if one acquires a habit of $\Phi$-ing, one thereby makes $\Phi$-ing one's own, and $\Phi$-ing is quite literally,

25 Sabina Lovibond in Moral Formation (Cambridge and London: Harvard University Press, 2002) argues that one is not properly the author of a moral judgement unless one 'seriously means' what it expresses, which is borne out by the commitment one shows in what else one says and does. Whilst I am indebted to her discussion, I reject what I take to be an intellectualist assumption on her part, namely, that judgement is necessary for action. The notion of authorship I offer is more primitive in the sense that it can be manifest in action alone; judgement need not enter the picture at all.

${ }^{26}$ A possible exception is McDowell who, in Mind and World, outlines a case for the general applicability of Aristotle's conception of ethical upbringing in his 'naturalism of second nature' (p. 84, and see also n. 16 above). 
part of who one is. When one thereafter $\Phi$-s, one expresses who one is in a way that was not possible without the habit.

This, then, is the second sense in which constitution features in our understanding of habits. The relation of habit to agent is not like that of action to habit, that is, one of constitution across time, for one's habits stretch as far forward and backward as that part of the agent does. However, it is also perhaps misleading to say that the relation is one of constitution at a time, since both habits and agents, on this conception, both, as it were, go back a long way. But as long as we think of the idea of constitution at a time as including temporally extended entities like habits, there should be no problem. At any given time, a given agent's set of habits are constituted over time, but are, at any given time, in a certain state of development. The same can be said of the agent herself.

One striking fact about habits as a source of authorship, and what makes them revolutionary in how we conceive of agency in analytic philosophy, is that they offer a construal of agency which is quite independent from psychological factors. The mode of acquisition of the habit, for instance, does not undermine the claim to authorship. One might after all, acquire a habit intentionally (that is, after a decision to do so) or inadvertently, and it might be thought that only habits in the former class properly express who one is. But even inadvertently acquired habits (such as the acquisition of an accent) reveal, to some degree, who one is. And the fact that one might have habits that one would rather not have, does not undermine the claim that they still confer agency. The fact that one still exercises the habit, despite efforts to the contrary, just shows that one has not managed to change who one is. Of course, many of our habits work in harmony with our psychology, which is to say that were we to reflect on what to do, we would choose to exercise our habits in the normal way. Psychology, as it were, allows, or gives our habits permission, to do their stuff. But that should not lead us to believe that it is this permissive psychology that confers authorship exclusively, when we can say that habits can do the job on their own.

The trained practical intellect is of course a powerful means of determining appropriate courses of action in many circumstances. We can undoubtedly cope more or less well with all sorts of unforeseen situations thanks to our intellectual capacities. But even if we grant the power of the intellect to work out that one should $\Phi$ in some novel context, the most in the way of authorship that such an operation of the intellect could achieve is the extent to which it was that person's intellect who worked it out. And, as I have tried to show, the intellect is not all there is to being that person. 
Perhaps more importantly, these movements of the intellect are at home not in our day-to-day interactions with our familiar environment and our friends and families, but in dealing with exceptions, with the unfamiliar; that which is alien to us, and we are still getting to know. So if we want to understand agency as it were, where it is most at home, we will introduce a serious distortion if we intellectualise these familiar performances, picturing our familiar routines as alienated encounters with the unusual. A methodological reason, then, for acknowledging that habits can be a source of agency, is that it allows us to avoid this distortion. And it is just this distortion which underlies not just Davidson's view, but also much of contemporary philosophy of action.

\section{Conclusion}

Davidson's causal thesis looks more plausible than it should because he runs together two very different sorts of pro attitude: those that are habits and those that are not. Whilst including habits amongst the pro attitudes is appealing because it allows us to unify that heterogeneous set which we call actions, it is at the cost of a serious distortion of a large class of our most familiar actions. The distortion begins by modelling habits along the lines of psychological states which are, in principle, separable from the actions which disclose them, and proceeds by tying those two items back together by means of a supposed causal relation.

But if we take the trouble to treat these two different sorts of pro attitude on their own terms, we can see that in many cases, this distortion is neither necessary nor helpful. We don't need it because other forms of explanatory relation, in particular the constitutive relation, may be more plausible. And, partly as a result, the unified scheme does not help us to understand the phenomena of action or agency in all their richness. For I have not claimed that the causal account does not work for some pro attitudes. And nor have I claimed that the teleological interpretation fails. For all I have said, these may work on their own terms with their own kinds of pro attitude. If this means we have to settle for a plurality of explanatory paradigms for action, this may be a better place to be at least for the time being. For it is better than continuing to labour under the illusion that unity has been discerned, when in reality it has been imposed.

One of Davidson's mistakes, then, is to conceive of agency as an essentially intellectual entity; the sort of thing whose psychology is driving actions in every case. But if our interest is in finding a philosophically accurate account of agency which represents human agents as we find them, we should resist any reduction of agency to psychology. For 
agents are constituted of other things besides. And though it may not support our aspiration to see ourselves as rational choosers in whatever we do, it is a serious error to forget that we are creatures of habit.

University of Edinburgh

School of Philosophy, Psychology and Language Sciences

David Hume Tower

George Square

Edinburgh EH8 9JX

Bill.Pollard@ed.ac.uk 